\title{
Fragmentation by design: universal health coverage policies as governmentality in Senegal
}

\section{Abstract}

There is increasing international consensus that countries need to reduce health system fragmentation in order to achieve universal health coverage (UHC). Yet there is little agreement on what drives fragmentation, in particular the extent to which fragmentation has a political purpose. This study analyses a highly fragmented health financing system through a UHC policy that aims to remove user fees for people aged 60 and over in Senegal. 53 semi-structured interviews (SSIs) and focus group discussions with the target population were conducted in four regions in Senegal over a period of six months during 2012. A further 46 SSIs were conducted with key informants at the national level and in each of the four regions. By analysing explanations of the successes and failures of policies, an understanding of power relations in state institutions, communities and individuals is gained. The concept of governmentality is used to interpret the results. The interviewees' main concern was to implement or resist various techniques of control over the conduct of bureaucrats, patients and the wider population. These techniques included numeracy and calculation, referral letters, ID cards, data collection, new prudentialism, active citizenship and ethical selfformation through affinities of the community. The techniques sought to make two different types of subjects; citizens subjects of rights and obligations; and autonomous subjects of choice and self-identity. A key implication is that in Senegal, and perhaps elsewhere, fragmentation of the health system plays a key 
role in the formation and control of subjects, in the name of "freedom". As such, fragmentation may be an inherent feature of UHC. Interventions that aim to reduce fragmentation based on evidence of its inefficiency, inequity and ineffectiveness in reducing poverty and ill health may be missing this point.

\section{Keywords}

Universal health coverage, Africa, Senegal, health systems, fragmentation, governmentality, citizenship, older people 


\section{Introduction}

\section{Fragmentation versus universal health coverage}

In 2005, the World Health Organization (WHO) adopted a resolution urging member states to achieve universal health coverage (UHC), defined as "access to key promotive, preventive, curative and rehabilitative health interventions for all at an affordable cost....", subject to the proviso that the cost of care "...[should] not put people at risk of financial catastrophe" (WHO, 2005). This commitment is affirmed by international initiatives (UNGA, 2015) and a global alliance (https://www.uhc2030.org/). The question now preoccupying policymakers and researchers is how best to design and implement such policies.

International consensus is moving towards a model that reduces fragmentation of the health system in order to enhance possibilities for income and risk crosssubsidies. Fragmentation refers to "the existence of a large number of separate funding mechanisms (e.g. many small insurance schemes) and a wide range of health-care providers paid from different funding pools. Different socioeconomic groups are often covered by different funding pools and served by different providers." (McIntyre et al., 2008). This type of health system fragmentation causes concern in low-and-middle-income countries (LMIC) and high-income countries (HIC) alike (Klasa et al., 2018; McIntyre et al., 2008; WHO, 2010).

Greatest international consensus has emerged around reducing fragmentation of revenue collection. Even the World Bank, a former proponent of user fees and 
private insurance, now joins WHO in arguing that mandatory, tax funded revenues should be the main source of health sector funds (Cotlear et al., 2015). In terms of risk pooling, both WHO and the World Bank express a preference for few pools or single-program UHC initiatives. Both agencies promote the central role of public providers but argue for the importance of engaging with the private sector to varying degrees (Cotlear et al., 2015; WHO, 2010).

Despite this increasing international consensus, there is a long way to go to achieving UHC. The global rate of catastrophic expenditure increased between 2000 and 2010, fastest in Africa (WHO and International Bank for Reconstruction and Development / The World Bank, 2017), and many health systems remain highly fragmented (Cotlear et al., 2015).

\section{The politics of $U H C$}

Critics argue that this lack of progress is in part due to the failure to recognize the political nature of UHC reforms. Programmes seeking to reduce health system fragmentation and enhance UHC are often reliant on standardized international models of health systems, underpinned by principles of health economics and technocratic evaluation (Gilson et al., 2011). Yet political economists studying determinants of UHC point to important factors such as institutions, policy cycles and ideology (Bump, 2010; Greer \& Mendez, 2015; Kelsall et al., 2016; Participants at the Bellagio Workshop on Political Economy of Global Health, 2015; Reich et al., 2016; Stuckler et al., 2010). Authors of this 
new wave of research hope their studies will lead to more effective UHC implementation, informed by appropriate academic theories and concepts.

However, a second body of political research is less optimistic. Rather than seeing gaps between UHC policy and practice as signs of programme failure, this latter approach argues these gaps are always already part of the policies themselves (Birn et al., 2016). These critics contend that "UHC as a global priority does not portend the creation of comprehensive, unified and single-tier health systems, but rather a cooptation of such approaches by privatized or semi-privatized, segmented and fragmented, 'pluralistic', profiteering, and ultimately inequitable arrangements for universalizing partial and insufficient health insurance coverage" (Birn et al., 2016). They point to the impossibility of reducing fragmentation in UHC without political transformation of wider hierarchical political and economic structures. While this argument has merit, it also has limitations, as it offers little scope for local actors' agency, or for practicable policy interventions.

\section{Governmentality: making citizen subjects and autonomous subjects}

Empirical data lead this study to adopt an alternative approach to the politics of UHC failure, which agrees that fragmentation is always already written into UHC policy, but at the same time argues for actors' agency and the possibility of localised progressive reform. Rather than being structurally determined, this study finds that political rationalities of UHC are constantly identified, defined and redefined by various actors at all levels of the health system. 
The specific concept adopted is neo-Foucauldian governmentality (Foucault, 1991), which emphasises the tactical practice of appropriation and repurposing of governmental techniques by a wide variety of actors in a fluid, diffuse and ongoing set of power relations. Governmentality is an understanding of government as the "conduct of conduct", encompassing all deliberate endeavors to shape, guide and direct human conduct, such as institutions, discourses and techniques for discipline and care of the self. The state becomes one element in multiple circuits of power, connecting diverse authorities and forces. In this way, the management of large-scale populations intersects with the management of individual conduct.

Central to the concept of governmentality is the concept of subjectification. Subjects are argued to only act and understand themselves within a historical field of possible experiences. This entails the study of rationalities and practices of government that generate the subject by invoking and legitimizing certain images of the self, while excluding others. Yet subjects also possess agency; in understanding themselves as a subject and working on themselves in alignment with this self-understanding, subjects not only reproduce power relations, but also transform them (Bröckling et al., 2011).

Neo-Foucauldian scholars have employed the concept of governmentality to analyse the shift from liberalism to so-called "neoliberal" policies. These scholars identify not a reduction of state sovereignty, as is often argued by critics of neoliberalism, but a displacement from formal to informal techniques of 
government that indicates a new relation between state and civil society actors (Bröckling et al., 2011; Ferguson \& Gupta, 2002; Rose, 1999).

Rose (1999) analyses these political transformations through the study of the invention, evolution and crisis of social insurance in HIC. He argues that in the 1980s, advanced liberal (he uses this term in place of "neoliberal") rationalities reconceptualized citizenship as "active", meaning that individuals are to conduct their life (and that of their family) as a kind of enterprise. Through this process, "autonomous subjects of choice and self-identity" are made. This advanced liberal rationality coexists with (rather than replaces) the preexisting liberal rationality, characterized by discretionary authority (obligation, duty, dependence) and the formation of "citizen subjects of rights and obligations". Crucially, he argues that it is the coexistence of liberal and advanced liberal political rationalities that drives social insurance fragmentation. Although this fragmentation is troubling, he argues it has an important political purpose; i.e. the creation of a control society based on the notion of freedom, or "government through freedom".

\section{Governmentality as a driver of health system fragmentation in LMIC?}

While studies of private health insurance in the USA draw on governmentality (Ericson et al., 2010; Ericson et al., 2003; Mulligan, 2014), the concept has surprisingly not been systematically employed to study UHC in LMIC. Yet, following Mkandwire (2011), the crisis of social insurance in HIC should be 
compared with inadequate social insurance programmes in LMIC, as both have been subject to policies of privatization and austerity.

This paper employs Senegal as a case study, in order to answer the following questions: "What power relations underpin and emerge from UHC policy within state institutions, communities and individuals? To what extent can analysing these power relations help explain health system fragmentation in Senegal and other LMIC?" In particular, the paper seeks to understand the extent to which health system fragmentation has a political purpose. A grounded methodology is adopted, asking the people who design, implement and use the health system in Senegal to explain UHC successes and failures and to suggest ways forward. This responds to the call for governmentality research to adopt more detailed empirical approach (Mckee, 2009).

The study finds that Rose's analysis of fragmentation of social insurance (1999) is useful for explaining fragmentation of UHC in Senegal, albeit with some adaptations. As in Rose, this study reveals a bewildering level of fragmentation and complexity, caused by progammes which sought to inculcate subjects alternately with rights and obligations, and choice and self-identity. The study argues that this fragmentation was not necessarily a dysfunction or result of poor implementation, but may be a key rationality of UHC in Senegal. This improved understanding of citizen and subject formation in the roll out of UHC in LMIC may lead to the development of more progressive and comprehensive UHC practices in those contexts (Dao \& Nichter, 2016; Ferguson, 2010; Prince, 2017). 
The following section provides background information on UHC in Senegal and a specific policy that will be analysed in depth. The methods are then presented, followed by further explanation of governmentality through its application to the empirical results.

\section{UHC in Senegal}

Senegal is one of the most stable democracies in SSA. Like many LMIC, since the 1980s it has undergone structural adjustment and a Poverty Reduction Strategy Programme. The reforms included cuts to public expenditures, privatization of major state enterprises and market deregulation (AFRODAD, 2006). A policy of user charges was introduced in the 1990s at all levels of the health system, under the WHO and UNICEF-sponsored Bamako Initiative (BI). By charging patients directly at the point of service use, the government sought to harness the power of market mechanisms and community development. Appeals for the empowerment of citizens to take responsibility for their health became ubiquitous (Foley, 2010). BI was accompanied by decentralisation of the health sector. These reforms aimed to enhance access to allopathic health services. Hospitals typically had very low levels of utilisation and provision was skewed to former colonial urban centres; most of the population therefore relied heavily on traditional medicine (Keita, 1996; Lemiere et al., 2012). The reforms granted hospitals autonomy of financial management and locally elected officials and health committees were made responsible for health budgets. Although health sector workers are paid a salary, the reforms enabled providers to top up salaries with cash raised by user fees and sales of pharmaceuticals. The reforms 
resulted in a rapid increase in hospital activity, but the benefits were not equally distributed. As elsewhere in SSA, user charges acted as a barrier to needed health care, increasing poverty and inequity (Foley, 2010).

In order to reduce high levels of out-of-pocket spending, Senegal introduced a set of user fee exemptions (MSAS, 2007). This study focuses on a specific user fee exemption named "Plan Sésame" (PS), which aims to provide free access to a comprehensive package of publicly funded and provided health care services to all Senegalese citizens aged 60 years and over - an estimated 5.9\% of the total population. As such, it is a policy that has the potential to promote UHC. PS was launched in 2006 along with a raft of other user fee exemption policies, including free deliveries and caesareans (Meessen et al., 2011). More recent efforts to expand user fee exemptions include a new policy aimed at children aged under 5 years (Daff et al., 2020).

User fee exemption is one of three pillars that make up Senegal's UHC programme, launched in 2013 (Daff et al., 2020; Ministère de la Santé et de l'Action Sociale, 2013). The second pillar is reforming health insurance institutions that cover workers and pensioners in the civil service and private sector. The third pillar is expanding coverage of community-based health insurance (CBHI) schemes.

These various health sector reforms have generated serious fragmentation. There are now multiple risk pools and health service providers' revenue is paid from a wide variety of sources, including central/local government; a private 
sector pension fund (Institut de Prévoyance Retraite du Sénégal - the Pension Insurance Institute of Senegal) (IPRES)); a civil servants' pension fund; employers; private health insurers; CBHI schemes; households; not-for-profit organizations; and donors. Payments are typically made using fee-for-service, in some cases combined with a global budget, but each source of revenue has its own administrative procedures, making the system complex and burdensome (Bossyns et al., 2018).

\section{Plan Sésame: a Senegalese user fee exemption policy}

PS in principle operates in all public health facilities, at all levels of care: health posts, health centers and hospitals. Hospitals are supposed to be pre-financed, with budgets transferred by the central government, while health centers and posts are reimbursed with pharmaceuticals from the National Drug Procurement Centre.

However, by the time of fieldwork in 2012, PS was hardly operational, making it a useful entry point to study UHC failure. PS had suffered from insufficient funding by the state, never exceeding around 800 million CFA (€1.2 million) per year. Hospitals had adopted a fee-for-service reimbursement model to finance PS, but payments were often delayed and the government accumulated a large debt to hospitals (totalling around 4 billion CFA by 2011) (Leye et al., 2013; Mbaye et al., 2013). Furthermore, only $10.5 \%$ of the target population was found to have ever used PS to access free health care (Ndiaye et al., 2014). Access (Parmar et al., 2014) and utilisation were highly inequitable, with wealthier, 
urban, formal sector people who already had relatively good access to other types of health insurance being relatively more likely to access free health care under PS (Ba et al., 2015). This unsuccessful experience with user fee removal echoes that of many other LMIC (Ridde et al., 2012).

\section{Methods}

A total of 34 SSIs and 19 focus group discussions (FGDs) with people aged 60 and over were conducted over a period of six months during 2012, across four regions in Senegal. Although the focus on older people limits the scope of the research, the interviewees represented a wide variety of socioeconomic profiles, as they were purposively selected from a household survey which preceded the qualitative study. As such, the SSIs and FGDs cover variations in: formal and informal sectors; gender; urban/rural residence; social status; and vulnerability.

A further 46 semi-structured interviews were conducted with key informants (KIs), including policymakers, doctors, nurses and other health sector workers. These were conducted at the national level and also in each of the four regions studied. KIs were selected using snowball sampling.

All SSIs and FGDs were of a focused, open-ended type and were conducted in local Senegalese languages, recorded, transcribed using verbatim transcription and translated. Informed consent was obtained. All transcripts were analysed using NVivo10, in order to identify lay explanations of causes of success and / or 
failure of PS and ideas for how to improve the policy and its implementation. The interview guides and background literature, especially Rose's (1999) study of governmentality, were used to develop a coding frame to deductively code the data. Inductive coding (Glaser, 1967) was then performed in order to add relevant codes to the coding frame. As new codes emerged all transcripts that had been previously coded were read again and new codes added where appropriate. Ethical approval for this research was obtained from the National Ethics Committee for Research in Health, Senegal [674/MSAS/DS/DER].

\section{Results}

The explanations for PS policy failure and suggestions for improvement raised by the interviewees are wide-ranging and complex. Yet the concept of governmentality, as interpreted by Rose (1999), provides a coherent overarching framework through which the findings can be understood and health system fragmentation explained, albeit with some adaptations. The results suggest that fragmentation was driven by interviewees' concern to implement or resist various techniques of discipline and control over the conduct of bureaucrats, patients and the wider population. The first set of techniques, presented in sections 1-4, sought to make liberal citizen subjects of rights and obligations. The second set, presented in sections 5-6, sought to make advanced liberal autonomous subjects of choice and self-identity. It was the coexistence of these two sets of techniques of subjectification that drove health system fragmentation. Yet the boundaries between the various techniques were often blurred and overlapping, as described in section 7. 


\section{Social insurance, solidarity and the social contract}

Rose (1999) argues social insurance was the central liberal technological innovation designed to respond to social fragmentation in Western society in the late $19^{\text {th }}$ century / early $20^{\text {th }}$ century. Individuals not only had the responsibility to gain employment in order to provide for themselves and the family, but the free citizen was also locked into a web of social solidarities and interdependencies - across the individual's life, across all individuals in the population and across generations. The contributory system and the fiction that there is a direct relation between the payments made by the individual and benefits received gained importance. This was a compact of social and individual responsibility.

In the interview results from Senegal, similar themes emerge. KIs and older people alike approvingly pointed to contributions of older people as justification for benefitting from PS. Several older people explained their ability to access free health care under PS as a result of making a rightful claim on the state based on their prior tax contributions. Yet unlike in Rose's case studies, in Senegal there are low rates of direct taxation and older people's contribution to society was seen to be far broader than paying taxes. Many KIs praised PS as a recognition of older people's lifetime of contribution to society:

... the elderly are important in society ... older people have promoted the development of solidarity... fostered social cohesion... (ESH-Ass-DS-27) 
This relationship between individual responsibility and social intergenerational solidarity was seen to be at the heart of the social contract that underpinned PS. This was lauded as an essential success factor in PS.

PS was also described as a "noble" policy because it revalorized older people in the face of loss of respect. In particular, some complained that economic wealth has overtaken age as a marker of respect. The KIs called this a "cultural crisis" or "cultural shift" brought about by the complex interaction of westernisation, urbanisation, poverty and the financial crisis, resulting in reduced familial support to those remaining in rural areas. Similarly to the birth of social insurance in the West, then, PS was seen to be an important remedy to cultural and financial crises in Senegal.

\section{Exercise of self-control}

Rose (1999) highlights an aspect of early twentieth century European social contract that is overlooked in the UHC policy literature; "techniques of the self". These techniques are injunctions to moral government formulated in terms of self-control developed in the $19^{\text {th }}$ century through guidance to parents, for example. This was an exercise of inhibition of the self by the self, individual responsibility at the heart of liberalism.

In Senegal, there was similarly a preoccupation among some KIs with the need for greater citizen responsibility to ensure PS success: 
Populations are responsible for not creating operational difficulties for the structures involved in management... (ESH-SS-MT-7)

Central to techniques of the self is the notion that individuals should calculate their benefit and weigh it up against their contribution and the contributions and needs of others. Numeracy and techniques of calculation therefore have an important role in subjectification. They furnish individuals with ways of thinking about, predicting and judging their own activities and those of others, engendering foresight and prudence. This transforms the way in which an individual thinks about themselves; each individual and their family are transformed into a calculative locale, planning the present in terms of the future through investment, pensions, insurance plans. It is partly through this process that a citizen subject of rights and obligations comes into being (Rose, 1999). Such a process of calculation was clearly evident in the interview results:

I have used Plan Sesame... I had heart disease, they did a radiograph. I was told I had to pay 30,000 CFA ${ }^{1}$... when I took bill ... the man ... said do you know how much this radiography normally costs? I said "No"! He said it cost 100,000 CFA. I told him "Why are you telling me that?" .... He said ... "It's just that I want you to be thankful to the Government". I said, "Do you know how long I've been paying taxes? Even one percent of what I've paid in taxes does not amount to that"... (FGD, Association of District Delegates, Dakar)

\footnotetext{
${ }^{1} 1,000 \mathrm{CFA}$ is equivalent to around $€ 1.50$.
} 
Calculating ability to pay was also encouraged. For example, one KI explained that his mother had been offered free care under PS but he had refused and voluntarily paid her bill, as he felt he could afford to do so. He expected everyone to be similarly self-motivated to make such calculations and sacrifices, epitomising inhibition of the self by the self:

I think PS must belong to everyone... we should not even wait to be instructed; each of us must be a defender of PS at his or her own level. (ESH-SS-DK-39)

He and other KIs therefore argued that failures of PS had occurred partly because citizens were irresponsible and had not done enough of this type of mental calculation.

\section{Discipline and resistance}

Rose (1999) argues that liberal forms of government are made possible through so-called "human technologies of government", a heterogeneous assemblage of forms of practical knowledge. These include not only techniques of the self, as discussed above, but also types of authority, for example. Through these technologies, the development of moral virtues of character such as self-reliance, self-restraint and self-improvement were promoted and kept constantly in view. These technologies are disciplinary but are not counterposed to freedom; 
"because what we have come to understand as our freedom is the mobile outcome of a multitude of human technologies" (Rose, 1999).

PS in Senegal constituted various technologies of government. One of these was the referral letter. Without a referral letter, patients could go directly to consult a specialist in a hospital, but would have to pay for their consultation and any treatment directly out of pocket. In contrast, in PS, patients were supposed to enter the health system at the primary care level and obtain referral letters in order to access higher levels of care, free of charge. This involved obtaining a referral letter signed by a district level doctor from a medical centre and a guarantee letter signed by the regional head doctor.

KIs explained that the referral system required people to "move up" the health pyramid ("la pyramide sanitaire"). The health pyramid represented a hierarchy of health service providers, with health huts and posts (most numerous) at the bottom, health centres in the middle, and hospitals at the top (least numerous). "Moving up the pyramid" took place through a set of intense physical processes. Older people complained of traveling long distances to obtain referral letters, queuing for hours, and being sent from one hospital or office to another. Being sick, elderly and living in a remote rural area made this bureaucracy especially arduous to navigate. These problems were exacerbated by the fact that a referral letter had a limited length of validity; it only lasted until the end of the month in which it was issued. 
Ostensibly, referral letters were intended to enhance efficiency of the health system:

There is... the referral system... to keep control of the costs, it should not be that whenever someone has a little fever, they show up at the hospital. (ESH-Inst-DK61)

However, the referral system was unlikely to enhance efficiency as it ultimately deterred PS utilization, with reports of people "tearing up" their letters in frustration. The letters were rather a means of shaping conduct, through discipline, requiring people to move through space and time in specific ways. This is akin to the Foucauldian notion of governing, where previously "irreal" divisions of time and space need to be constructed through mechanisms that define their boundaries, make them visible and make it possible to assemble information about them (for example, spaces such as nations are delineated and time is cut up into units) (Rose, 1999). Indeed, for many of the older people interviewed, the referral letters made the abstract "health pyramid" "real" for the first time.

Perhaps unsurprisingly, some patients tried to enter the health system at the top of the pyramid by consulting a hospital doctor directly, without obtaining a referral letter, and still access free care under PS. KIs described this as "not respecting the health pyramid". KIs also spoke disparagingly of patients "abusing" PS by seeking out health worker friends and relatives to provide them with health services they did not really need. KIs argued that doctors needed to be 
more "courageous" in counteracting this "abuse" of the system from patients, adopting a moralising tone which denounced abusers' perceived waste of public resources.

Patients' so-called "abuse" of the referral system can be interpreted as resistance to the disciplinary mode of government and type of morality promoted by the KIs. This follows the Foucauldian notion of resistance not as liberation from an oppressor, but rather as subjects' invention of alternatives to current governing practices (Mckee, 2009). Older people concurred that health workers gave preferential access to PS to their families and friends by providing them with information and services ahead of other patients, but unlike the KIs, they did not portray this as a form of "abuse". Under this alternative morality, it was correct for health workers to provide better access to PS to close friends or relatives. Several interviewees called this process the "buddy system" ("system camarade" in French) (Mladovsky \& Ba, 2017).

A further form of resistance was the practice of paying for or using social influence to obtain a referral letter, which led to great inequity in the utilisation of PS:

I've never tried (to obtain PS referral letters) because I know I will not get them, I am poor. (FGD, men who attend public community meetings (les « Grand-Place »), Dakar) 
Several older people described this system as the "long arm" ("bras longue" in French), denouncing it as immoral, as unlike the buddy system it was not based on friendship or affect (Mladovsky \& Ba, 2017). In contrast, no stakeholders explicitly mentioned the "long arm". A few used the term "clientelism" to refer to this phenomenon, while others referred to it only obliquely:

...(some older people) can use health facilities because they have cultural ability, they have a network, they have relationships... (ESH-Ass-DK-36)

A second human technology discussed by KIs was ID cards. In Senegal, some KIs expressed a concern that people younger than 60 and people from countries neighbouring Senegal were trying to use PS services. They explained that the use of the ID card in PS was intended to mitigate against this - in order to access PS patients had to present a valid national ID card at the health service provider to prove one's age and Senegalese citizenship. Interviewees reported no major bureaucratic problems obtaining a national ID card. This is supported by the results of a household survey (Parmar et al., 2014). As with the referral system, ID cards allow the state to "see" citizens better. Indeed, ID cards are a classic example of a disciplinary human technology that makes citizens and nations "real", through surveillance, data and normalization (i.e. the construction of an idealized norm of conduct) (Lyon \& Bennett, 2008). However, in Senegal, this technology was also resisted; for example KIs complained that people aged below 60 were fraudulently using the ID cards of people aged 60 or over in order to benefit from free care under PS. 
Rose (1999) analyses the construction of morality through governmentality, but does not explicitly address corruption and fraud, representing something of an oversight. However, in the context of India, neo-Foucauldian scholar Gupta (2012) views the sense of pervasive corruption in state welfare programmes as a productive discourse that instils notions of citizenship, rights and accountability in the population. At the same time, corruption discriminates against those who do not have the resources to obtain goods and services that are supposed to be provided free of charge through programmes of social welfare. He argues this creates a troubling paradox; the developmental state excludes the very people on whom its popular sovereignty rests. There was a similar paradox at play in PS. As a disciplinary programme of social welfare, it sought to create citizen subjects, but it also opened up new opportunities for corruption and the resulting exclusion of those same citizens.

\section{Population data for moral order}

Rose's (1999) concern with technologies that promote "moral order" focuses on the "invention of the social", a shift that occurred in Europe and the USA at the start of the twentieth century, arising out of the documentation and conceptualization of populations through statistics, censuses and surveys. This documentation aimed to render "moral events" knowable and calculable. The moral order, which had once been justified by reference to extrinsic theological principles, mutated into a reality with its own regularities, laws and characteristics. 
In PS, KIs frequently argued that more bureaucrats should be hired to collect and analyse more data on PS and that more funding was required to transport civil servants to the regions for better monitoring of PS. This improved data collection was argued to be a panacea for two forms of perceived immorality.

Firstly, several KIs argued there had been excessive supply of health services under PS because doctors had referred patients for too many diagnostic tests and had provided unnecessary services, in order to increase revenue generated by the fee-for-service system. A proposed solution was increased regulatory control over prescribing and referrals through a modern electronic health information system.

Secondly, many KIs argued there was a problem of misappropriation of PS funds by hospitals. They asserted that personnel in hospitals overbilled the government and pocketed the difference; or they charged patients a user fee and simultaneously claimed reimbursement from PS for the same intervention. They argued that without rectifying fraud, it was impossible to evaluate how much funding was needed to implement PS effectively and to ascertain the true size of the debt owed to health service providers by the government due to delayed reimbursement. Some proposed better health information systems as a solution to this. Others advocated a financial audit of PS, to uncover the fraud that had occurred.

In short, there was a widespread desire among KIs to generate more data in order to enhance morality in PS. 


\section{Freedom and "new prudentialism"}

Summarising the results so far, as in the case of social insurance in late $19^{\text {th }}$ / early $20^{\text {th }}$ century Europe, PS was made up of human technologies of government such as calculation, the referral system and ID cards; and the desire for more data collection to enhance moral order. These disciplinary technologies sought to make liberal citizen subjects of rights and obligations. Despite multiple points of resistance, many people enthusiastically complied with PS, or supported it in principle, arguing for its benefits and viewing it as a "noble" policy. However, the following sections identify ways in which features of a different rationality, advanced liberalism, were also inherently part of PS. This rationality sought to make autonomous subjects of choice and self-identity. It was the coexistence of these two rationalities that drove health system fragmentation.

Rose (1999) describes how in many Western states, from the 1970s onwards, all aspects of social behavior are reconceptualized along economic lines - as calculative actions undertaken through the universal human faculty of choice. Whereas previously programmes of social welfare were perceived to provide necessary instruments for the management of the national economy, the economic and social are now seen as antagonistic and economic government is seen to require "desocialisation". The role of politics is to provide conditions for active citizenship and entrepreneurship. As part of this shift, social insurance is no longer seen as a socializing and responsibilizing principle of solidarity. 
Similar rationalities were at play in PS:

It is as if older people living in the rural world have been unable to absorb the favour (i.e. PS) that had been offered to them. (ESH-SS-DL-30)

Strikingly, this KI does not use rights or social contract based language to describe PS, describing it instead as a "favour". Indeed, many older people were ambivalent about their right to health care:

In terms of health care, I expect the government to help us... If it helps me in terms of health care, I will take it, if it does not help me, I accept it and say, well it's me who cannot afford it. (FGD, female beggars, Dakar)

This focus on self-reliance resonates with the ethos of user fee system introduced prior to PS. Similarly, not all KIs approved of the disciplinary nature the referral system, arguing that it constrained freedom. They argued that patients should be liberated to choose the point at which they enter the health system:

I think people should be set free, so they can make their own choice of provider... (ESH-SS-DL-34)

Rose argues that in this context of "desocialization", those who can afford it choose to provide for their own security by the application of their own funds 
into private insurance and pension schemes; while those who cannot will be subject to what are perceived as psychologically deleterious and financially inadequate consequences of the benefit culture in the public sector. Hence all individuals, not just the well off, would benefit from providing their own security. This is termed "new prudentialism". The person who is prudent is no longer mutualized, but is an active citizen, autonomized and providing for their own security. This is also reflected in the results.

During its initial development, PS was intended to benefit the informal sector only and was to be named "Plan Sésame Paysan, Pasteur, Pêcheur (PPP)" ("Plan Sésame Peasant, Shepherd, Fisher"). However, eventually the formal sector was added, in the form of public sector pensioners (e.g. from the civil service), and IPRES members. In Senegal, since 1982, IPRES has provided health insurance coverage and dedicated services in IPRES health centres to private sector pensioners and their families. IPRES pays into PS funds so that their members can use PS to cover co-payments (IPRES did not reimburse its members for $100 \%$ of their health expenditures).

Several KIs said that IPRES members had realized it was simpler to bypass IPRES and claim full coverage for their health care under PS, by presenting their national ID card instead of IPRES cards at the hospital. Many KIs found this to be another form of "abuse" of PS. Indeed, survey data shows that formal sector pensioners were far more likely to know about PS than their informal sector counterparts, resulting in great inequity in access to PS (Parmar et al., 2014). 
IPRES pensioners said they sometimes used PS instead of IPRES, but did not describe this as "abusive". They argued that IPRES health centres did not offer a comprehensive set of health services, sometimes necessitating the use of state health providers under PS. Also, some IPRES pensioners said they switched to using PS at a nearby public hospital or health centre, rather than traveling long distances to an IPRES health centre.

Many KIs suggested introducing various disciplinary technologies in order to prevent IPRES members from using PS in this way. Some argued that access to PS should be means tested. Others argued that special colour-coded PS cards should be issued to informal sector workers and IPRES members respectively, to stop formal sector pensioners from "abusing" the system. These cards would be linked to electronic patient records. One KI said the government had issued a call for tender to implement this card scheme, but the plan not been followed through.

In short, many KIs argued that wealthy and formal sector IPRES pensioners should not use PS, or should have limited access to PS. These KIs were, by implication, stating that the social contract represented by PS should be reserved only for those who have no ability to make other choices - this can be seen as an example of "new prudentialism". The coexistence of IPRES and PS, and the ongoing debate about which type of person should be covered by which scheme, was a major driver of health system fragmentation and complexity.

\section{6. "Ethico-politics"}


Rose (1999) argues that subjects of advanced liberal technologies of government are obliged to think ethically, as techniques of citizen formation are no longer about the inculcation of externally validated morals. In this context, community becomes the new moral and ethical field binding persons into durable emotional relationships. The new community is a technology through which individual identities are constructed through their bonds to diverse micro-cultures of values and meanings. Rose terms the political objectification and instrumentalisation by government of this type of community as "ethicopolitics". These communities are spaces of ethical dispute, where subjects can invent themselves through techniques and styles of self-reflection and selfmanagement, outside of the control of overarching discourses of morality and civility, or technologies of political government. Over the second half of the twentieth century, an array of technologies was invented to make communities real. In this way, the tasks of knowing and governing have been dispersed through a myriad of micro-centres of knowledge and power.

Since the late 1990s, Senegal has witnessed a rapid increase in the number of CBHI schemes (reaching 129 in 2007 (CAFSP, 2010)) and other types of community-based organisations (Bernard et al., 2008). In the interviews, some older people reported using both CBHI and PS. CBHI aims to provide health insurance through voluntary prepayment of premiums by community members; it is not-for-profit and aims to be community owned and controlled (Mladovsky et al., 2014). However, studies have found that CBHI in Senegal had very low enrolment rates and was highly inequitable; it was likely to favour individuals 
who already possessed social, economic, cultural and other forms of capital and social power (Mladovsky, 2014; Mladovsky et al., 2014).

Nevertheless, the government elected in 2012 viewed CBHI as a key mechanism for achieving UHC. In order to address inequity in CBHI coverage, it introduced a policy of subsidising CBHI premiums of the poor. This caused a rapid expansion in membership; by 2016, there were 671 CHBI schemes, covering $16 \%$ of the population, with nearly two thirds of members being subsidized by the state (Agence de la CMU, 2017).

As in Rose's analysis of ethico-politics, CBHI in Senegal represented a diverse array of micro-cultures of values and meanings. There were, for example CBHI schemes exclusively for members of certain Muslim brotherhoods, or for Catholics, or for people living in a certain district or village (Mladovsky et al., 2015). In each type of scheme, communities were expected to choose which model of CBHI to adopt and which population groups or services to cover, according to their own ethical principles, often leading to fierce ethical debates. Some CBHI members, leaders and promoters derived aspects of their selfidentity through CBHI, claiming they embodied CBHI values such as solidarity and mutuality, for example (Mladovsky et al., 2015). CBHI and other communityled health financing initiatives were presented by government officials as examples of what responsible, active citizens should do to help themselves and the state find solutions to the problems of rural communities (Kane, 2010; Mladovsky et al., 2015). 
Yet these local ethics were often derived from communities' relationships with various global actors, mediated by the state to varying degrees. These included communities' longstanding links with international religious movements, as well as more recent relationships with the United States Agency for International Development (USAID), which provided technical assistance to CBHI managers (Mladovsky et al., 2015). Unfortunately, Rose pays little attention to the role of international organisations in the development of community ethics, or indeed in governmentality more generally. This critique of Rose is taken up by Ferguson and Gupta (2002), who argue for the study of state and nonstate governmentality within a common frame, in order to better understand the reconfiguration of states' authority through these transnational linkages.

The ethico-politics of CBHI contributed significantly to health system fragmentation, although the introduction of subsidies has attenuated some of the freedom of choice and ethical diversity, as the package of care is now standardised and centrally regulated (Agence de la CMU, 2017).

Two recent projects aim to reduce CBHI's role in health system fragmentation further. Firstly, a pilot project conducted in 2019 in partnership with the World Bank and USAID integrated free health-care initiatives such as PS into CBHI, so that exempted services are only offered free of charge to eligible people if they are also enrolled in CBHI. Secondly, the government is planning an integrated CBHI management information system (Daff et al., 2020). 
In sum, CBHI was a driver of health financing fragmentation, both in itself as a form of ethico-politics and in conjunction with PS. Recent reforms seek to reduce this fragmentation, while respecting CBHI autonomy. This technique of advanced liberal government promotes the ostensibly paradoxical twin projects of respecting the autonomy of certain "private" zones and at the same time shaping their conduct in ways conducive to fostering self-organization and active citizenship (Rose, 1999).

\section{Fragmentation: a control society based on the notion of "freedom"}

Rose (1999) argues that new advanced liberal technologies of government do not replace, but rather sit alongside, the old ones. This makes for a situation of bewildering complexity, as politicians and professionals cycle rapidly through the different options. There is therefore a multiplication of possibilities and strategies deployed around different problematizations in different sites and with different objectives.

Similarly in Senegal, several KIs argued that the coexistence of PS, IPRES and CBHI, as well as the multiple other user fee exemption schemes, was driving fragmentation of the financing system. Health service providers explained they found it difficult to keep up with the various successive reforms. For example, a health worker in a rural health hut complained he was still busy developing ways to implement user charges effectively and that it was difficult to simultaneously implement user fee removal for certain population subgroups. 
In light of this fragmentation and confusion, several KIs advocated for the development of one universal state funded health insurance scheme. This latter policy was never adopted, but from 2014 to 2016, two of Senegal's 45 departments piloted departmental health insurance schemes. This governmentprovided approach is based on risk pools that represent building blocks for a uniform nation-wide health insurance mechanism and institute, although membership remains voluntary (Bossyns et al., 2018; Ridde et al., 2018). As such, the fragmented approach to health financing continues in Senegal.

\section{Discussion}

This study has found evidence of an overt tactical practice of appropriation and repurposing of governmental techniques by a wide variety of actors in a fluid, diffuse and ongoing set of power relations. The interviewees' main concern was to implement or resist various techniques of control over the conduct of bureaucrats, patients and the wider population. These techniques sought to make two different types of subjects through the highly fragmented Senegalese health financing system; citizen subjects of rights and obligations in PS; and autonomous subjects of choice and self-identity in IPRES and CBHI.

The results suggest that PS represented a disciplinary and often resisted liberal logic, characterised by human technologies of government such as calculation, the referral system and ID cards; and the desire for more data collection to enhance moral order. Meanwhile, IPRES and CBHI were characterised by an 
advanced liberal logic of control, featuring: probabilistic technologies ("new prudentialism"); active citizenship; and ethical self-formation through affinities of the community ("ethico-politics").

In Rose's study, the emergence of the so-called "control society" does not amount to a shift to a new type of society - from discipline to control. Rather, new technologies of control sit alongside the old disciplinary ones. Subjects move, or are moved, between them. In the Senegalese case, these technologies were introduced in the reverse order; old disciplinary technologies like PS are introduced into a health system already characterised by advanced liberal forms of control like CBHI. Yet as in Rose's cases, the technologies coexisted.

Just as Rose argues that the categorisation of who is included and excluded in which social protection scheme is not a neat one, in Senegal policymakers debated and argued about which population group should be covered by which type of scheme and how to organise this coverage. Relatively privileged people who were already enrolled in private health insurance schemes (IPRES and CBHI), who made under-the-table payments, or who had certain types of social or familial networks, made greater use PS. This led some to argue that PS was inequitable and should be reserved for the poor and socially excluded. Meanwhile, many rural, socially excluded older people were unable or unwilling to gain access to PS and were targeted with state subsidies to enrol in CBHI, which became increasingly regulated by the state. Some people were no longer permitted to use PS without first enrolling in a CBHI scheme. Hence there was no single overarching rationality. It was the desire to create citizen subjects of 
rights and obligations and autonomous subjects of choice and self-identity that generated health system fragmentation. This suggests that fragmentation was always already part of UHC policy itself.

Following Rose, it could be argued that as in HIC, this fragmentation made it possible to imagine, if not actually create, a control society based on the notion of freedom in Senegal. This is because the so-called freedom offered by postdisciplinary health insurance in IPRES and CBHI was only possible if those deemed to be flawed consumers - unwilling or unable to organise and purchase insurance for themselves - received forms of welfare that exerted greater discipline.

The argument that UHC in Senegal was a form of governmentality diverges from the common understanding of "politics" in the UHC literature. Awareness of the importance of the politics of UHC is increasing among policymakers and researchers, but it is typically conceptualised as an expression of societal values, such as solidarity, inculcated through law or parliamentary acts (WHO, 2010), or as a governance challenge for political leaders, institutions, interest groups and other actors in the political system (Greer \& Mendez, 2015; Reich et al., 2016). Governmentality implies a more diffuse form of politics of UHC; namely efforts to develop of a certain type of society through the formation of certain types of subjects inculcated with certain behaviours and attitudes, through a set of power relations that may be enacted and contested by all actors interacting with the health system. 
Although policy recommendations are beyond the scope of this study, the findings should nevertheless be of relevance to policymakers. As Ferguson (2010) argues in the context of SSA, having an understanding of governmental techniques makes it possible to repurpose them and put them to work in the service of progressive political projects. This is likely to apply to UHC policymakers in Senegal and other LMIC, given the global nature of UHC policy, the widespread problem of health system fragmentation and the commonalities in governmental techniques across diverse contexts.

A further policy implication is that the definition of UHC, namely that all people have access to health services and do not suffer financial hardship paying for them, does not reflect its political purpose. This study suggests that subjectification, or the creation of citizen subjects and autonomous subjects, could be recognised as a goal of UHC, in order to better reflect its inherently political nature.

The other contribution of importance to policymakers is that by highlighting commonalities between drivers of fragmentation of social welfare in HIC and Senegal, this study may serve to counter negative stereotypes about chaotic bureaucracies in the global South. This paper suggests that all health systems may be inherently chaotic, not necessarily because of some inadequacy (although many are inadequate), but because an important purpose of health systems, namely creating subjects, might be even more complex than the formidable task of promoting health. 


\section{Conclusion}

UHC policy in Senegal sought to create citizen subjects of rights and obligations and autonomous subjects of choice and self-identity, in the development of a control society based on the notion of freedom. These processes drove health system fragmentation in Senegal. The creation of specific types of subjects as a cause of fragmentation of UHC has been overlooked by other approaches to analyzing politics of UHC.

A key implication of this research is that in Senegal, and perhaps elsewhere, the fragmentation and complexity of the health system, with policymakers and patients repeatedly cycling between various options, is not necessarily a dysfunction or result of poor implementation, but is an inherent feature of, and may even partly define, UHC. Interventions that aim to remove or reduce this fragmentation based on evidence of its inefficiency, inequity and ineffectiveness in reducing poverty and ill health, may be missing this point. Further research is needed to investigate whether efforts to reduce health system fragmentation more recently in Senegal and elsewhere bear out this argument.

Recoginsing that UHC has a political goal of forming citizen subjects and autonomous subjects could help in the development of more progressive governmental techniques. At the same time, it avoids attributing failure to structural factors that overpower any specific actor or set of actors, or to stereotypical notions of inherently chaotic bureaucracies in the global South. 
Just as in Rose's analysis of social welfare in HIC, in Senegal and perhaps elsewhere, UHC as governmentality may constitute the ostensibly paradoxical attempt to govern through "freedom". The broad appeal of this ostensible paradox arguably explains the enduring nature of the bewilderingly complex and fragmented health systems it underpins, both in HIC and in LMIC. 


\section{References}

AFRODAD (2006). Macroeconomic Policy Options in Sub - Saharan Africa: Linking Poverty Reduction Strategy Papers (PRSPs) and the Millennium Development Goals. The Case of Senegal: www.eurodad.org/uploadedfiles/.../eurodad\%20afrodad\%20senegalmd gsprsps.doc Accessed 12/11/18.

Agence de la CMU (2017). Mise en œuvre de la couverture maladie universelle: rapport d'activités de l'année 2016: Ministère de la Santé et de l'Action Sociale, République du Sénégal.

Ba, M., Dkhimi, F., \& Ndiaye, A. (2015). L'impact des modalités d'allocation des ressources dans les mécanismes d'exemption sur l'équité : Plan Sésame, Sénégal. African Health Monitor, 20, 63 - 66.

Bernard, T., Collion, M.H., Rondot, P., Sadoulet, E., \& De Janvry, A. (2008). Do Village Organizations Make a Difference in African Rural Development? A Study for Senegal and Burkina Faso. World Development, 36, 2188-2204.

Birn, A.E., Nervi, L., \& Siqueira, E. (2016). Neoliberalism Redux: The Global Health Policy Agenda and the Politics of Cooptation in Latin America and Beyond. Development and Change, 47, 734-759.

Bossyns, P., Ladrière, F., \& Ridde, V.r. (2018). Une assurance maladie à grande échelle pour le secteur informel en Afrique subsaharienne

Six ans d'expérience au Sénégal rural. 2012 - 2017. Studies in Health Services Organization \& Policy, 34. Antwerp: ITG Press.

Bröckling, U., Krasmann, S., \& Lemke, T. (2011). From Foucault's Lectures at the Collège de France to Studies of Governmentality: An Introduction. In U. 
Bröckling, S. Krasmann, \& T. Lemke (Eds.), Governmentality: current issues and future challenges. London: Routledge.

Bump, J.B. (2010). The long road to universal health coverage: a century of lessons for development strategy

. Seattle, WA: PATH.

CAFSP (2010). Stratégie nationale d'extension de la couverture du risque maladie des sénégalais (Partie 1, Régimes contributifs volontaires) (National strategy for the expansion of coverage against the risk of ill health in Senegal (Part 1 voluntary contribution schemes)). Dakar.

Cotlear, D., Somil Nagpal, Owen Smith, Tandon, A., Rafael, \& Cortez (2015). Going Universal: How 24 Developing Countries are Implementing Universal Health Coverage Reforms from the

Bottom Up. Washington, DC: World Bank.

Daff, B.M., Diouf, S., Diop, E.S.M., Mano, Y., Nakamura, R., Sy, M.M., et al. (2020). Reforms for financial protection schemes towards universal health coverage, Senegal. Bull World Health Organ, 98, 100-108.

Dao, A., \& Nichter, M. (2016). The Social Life of Health Insurance in Low- to Middle-income Countries: An Anthropological Research Agenda. Med Anthropol Q, 30, 122-143.

Ericson, R.V., Barry, D., \& Doyle, A. (2010). The Moral Hazards of Neo-liberalism: Lessons from the Private Insurance Industry. Economy and Society, 29, 532-558.

Ericson, R.V., Doyle, A., \& Barry, D. (2003). Insurance as governance. Toronto ; London: University of Toronto Press.

Ferguson, J. (2010). The Uses of Neoliberalism. Antipode, 41, 166-184. 
Ferguson, J., \& Gupta, A. (2002). Spatializing states: toward an ethnography of neoliberal governmentality. American ethnologist, 29, 981-1002.

Foley, E.E. (2010). Your pocket is what cures you : the politics of health in Senegal. New Brunswick, N.J.: Rutgers University Press.

Foucault, M. (1991). Governmentality. In G. Burchell, C. Gordon, P. Miller, \& M. Foucault (Eds.), The Foucault effect : studies in governmentality : with two lectures by and an interview with Michael Foucault. London: Harvester Wheatsheaf.

Gilson, L., Hanson, K., Sheikh, K., Agyepong, I.A., Ssengooba, F., \& Bennett, S. (2011). Building the field of health policy and systems research: social science matters. PLoS Med, 8, e1001079.

Glaser, B.G. (1967). The discovery of grounded theory : strategies for qualitative research. New York: Aldine de Gruyter.

Greer, S.L., \& Mendez, C.A. (2015). Universal Health Coverage: A Political Struggle and Governance Challenge. Am J Public Health, 105 Suppl 5, S637-639.

Gupta, A. (2012). Red tape : bureaucracy, structural violence, and poverty in India. Durham: Duke University Press.

Kane, A. (2010). Charity and self-help: Migrants' social networks and health care in the homeland. Anthropology Today, 26, 8-12.

Keita, M. (1996). The Political Economy of Health Care in Senegal: The Integration of Traditional and Modern Health Care Revisited. Journal of Asian and African Studies, 31, 145.

Kelsall, T., Hart, T., \& Laws, T. (2016). Political settlements and pathways to universal health coverage: ODI Working Paper 432. 
Klasa, K., Greer, S.L., \& van Ginneken, E. (2018). Strategic Purchasing in Practice: Comparing Ten European Countries. Health Policy, 122, 457-472.

Lemiere, C., Turbat, V., \& Puret, J. (2012). A Tale of Excessive Hospital Autonomy: An Evaluation of the Hospital Reform in Senegal. Health, Nutrition, and Population (HNP) Discussion Paper. Washington: World Bank.

Leye, M.M.M., Diongue, M., Faye, A., Coumé, M., Faye, A., Tall, A.B., et al. (2013). Analyse du fonctionnement du plan de prise en charge gratuite des soins chez les personnes âgées «Plan Sésame » au Sénégal. Sante Publique, 25, 101-106.

Lyon, D., \& Bennett, C.J. (2008). Playing the ID card: Understanding the significance of identity Card Systems In C.J. Bennett, \& D. Lyon (Eds.), Playing the identity card : surveillance, security and identification in global perspective

. London: Routledge.

Mbaye, E.M., Ridde, V., \& Ka, O. (2013). ["Good intentions are not enough": analysis of a health policy for the elderly in Senegal]. Sante Publique, 25, 107-112.

McIntyre, D., Garshong, B., Mtei, G., Meheus, F., Thiede, M., Akazili, J., et al. (2008). Beyond fragmentation and towards universal coverage: insights from Ghana, South Africa and the United Republic of Tanzania. Bull World Health Organ, 86, 871-876.

Mckee, K. (2009). Post-Foucauldian governmentality: What does it offer critical social policy analysis? Critical Social Policy, 29, 465-486.

Meessen, B., Hercot, D., Noirhomme, M., Ridde, V., Tibouti, A., Tashobya, C.K., et al. (2011). Removing user fees in the health sector: a review of policy 
processes in six sub-Saharan African countries. Health Policy Plan, 26 Suppl 2, ii16-29.

Ministère de la Santé et de l'Action Sociale (2013). Plan stratégique de développement de la Couverture Maladie Universelle au Sénégal 2013-2017 République du Sénégal.

http://www.coopami.org/fr/countries/countries/senegal/social protecti on/pdf/social protection05.pdf Accessed 12/11/18.

Mkandawire, T. (2011). Welfare Regimes and Economic Development: Bridging the Conceptual Gap. Overcoming the Persistence of Inequality and Poverty, $149-171$

Mladovsky, P. (2014). Why do people drop out of community-based health insurance? Findings from an exploratory household survey in Senegal. Soc Sci Med, 107, 78-88.

Mladovsky, P., \& Ba, M. (2017). Removing user fees for health services: A multiepistemological perspective on access inequities in Senegal. Soc Sci Med, $188,91-99$.

Mladovsky, P., Ndiaye, P., Ndiaye, A., \& Criel, B. (2015). The impact of stakeholder values and power relations on community-based health insurance coverage: qualitative evidence from three Senegalese case studies. Health Policy Plan, 30, 768-781.

Mladovsky, P., Soors, W., Ndiaye, P., Ndiaye, A., \& Criel, B. (2014). Can social capital help explain enrolment (or lack thereof) in community-based health insurance? Results of an exploratory mixed methods study from Senegal. Soc Sci Med, 101, 18-27. 
MSAS (2007). Stratégie nationale d'extension de la couverture du risque maladie des sénégalais ; (National strategy for the expansion of coverage against the risk of ill health in Senegal) MSAS, Évaluation des initiatives de subventions et du fonds socials (Evaluation of funded initatives and social funds). Dakar.

Mulligan, J.M. (2014). Unmanageable care : an ethnography of health care privatization in Puerto Rico: NYU Press.

Ndiaye, A., Ba, M., \& Soors, W. (2014). Senegal and Plan Sésame. In Health Inc Consortium (Ed.), Towards equitable coverage and more inclusive social protection in health. Studies in Health Services Organisation and Policy (SHSOP) (32). Antwerp: ITG Press.

Parmar, D., Williams, G., Dkhimi, F., Ndiaye, A., Asante, F.A., Arhinful, D.K., et al. (2014). Enrolment of older people in social health protection programs in West Africa--does social exclusion play a part? Soc Sci Med, 119, 36-44.

Participants at the Bellagio Workshop on Political Economy of Global Health (2015). Report from Bellagio: advancing political economy of global health to understand and influence the drivers of universal health coverage. Health Syst Reform, 1, 20-21.

Prince, R.J. (2017). Universal Health Coverage in the Global South: New models of healthcare and their implications for citizenship, solidarity and the public good. . Michael, 14, 153-172.

Reich, M.R., Harris, J., Ikegami, N., Maeda, A., Cashin, C., Araujo, E.C., et al. (2016). Moving towards universal health coverage: lessons from 11 country studies. Lancet, 387, 811-816. 
Ridde, V., Asomaning Antwi, A., Boidin, B., Chemouni, B., Hane, F., \& Toure, L. (2018). Time to abandon amateurism and volunteerism: addressing tensions between the Alma-Ata principle of community participation and the effectiveness of community-based health insurance in Africa. BMJ Glob Health, 3, e001056.

Ridde, V., Robert, E., \& Meessen, B. (2012). A literature review of the disruptive effects of user fee exemption policies on health systems. BMC Public Health, 12, 289.

Rose, N. (1999). Powers of freedom : reframing political thought. Cambridge: Cambridge University Press.

Stuckler, D., Feigl, A.B., Basu, S., \& McKee, M. (2010). The political economy of universal health coverage. Background to the Global Symposium on Health Systems Research. Montreux, 16-19 November.

UNGA (2015). Transforming Our World: the 2030 Agenda for Sustainable Development.” United Nations General Assembly. Retrieved August 25, 2016 http://www.un.org/ga/search/view doc.asp?symbol=A/RES/70/1\&Lang $=\underline{E}$.

WHO (2005). Resolution WHA58.33. Sustainable health financing, universal coverage and social health insurance. Fifty-eighth World Health Assembly. Geneva: World Health Organization.

WHO (2010). The world health report. Health systems financing: the path to universal coverage. Geneva: World Health Organization. 
WHO and International Bank for Reconstruction and Development / The World Bank (2017). Tracking universal health coverage: 2017 global monitoring report. 